\title{
Commentary \\ Re-examining ethical obligations in the intensive care unit: HIV disclosure to surrogates
}

\author{
Anthony T Vernillo ${ }^{1}$, Paul R Wolpe ${ }^{2}$ and Scott D Halpern ${ }^{3}$
}

\begin{abstract}
${ }^{1}$ New York University College of Dentistry, Department of Oral and Maxillofacial Pathology, Radiology and Medicine, New York, New York 10010, USA ${ }^{2}$ University of Pennsylvania, Departments of Psychiatry, Medical Ethics, and Sociology and Center for Bioethics, Philadelphia, Pennsylvania 19104, USA ${ }^{3}$ Division of Pulmonary, Allergy, and Critical Care Medicine; Center for Clinical Epidemiology and Biostatistics; Center for Bioethics, University of Pennsylvania School of Medicine, Philadelphia, Pennsylvania 19104, USA
\end{abstract}

Corresponding author: Anthony Vernillo, atv1@nyu.edu

Published: 18 April 2007

This article is online at http://ccforum.com/content/11/2/125

(c) 2007 BioMed Central Ltd
Critical Care 2007, 11:125 (doi:10.1186/cc5720)

\begin{abstract}
Physicians treating newly incapacitated patients often must help navigate surrogate decision-makers through a difficult course of treatment decisions, while safeguarding the patient's autonomy. We offer guidance for intensive care physicians who must frequently address the difficult questions concerning disclosure of confidential information to surrogates. Three clinical vignettes will highlight the ethical challenges to physician disclosure of a critically ill patient's HIV status. Two key distinctions are offered that influence the propriety of disclosure: first, whether HIV infection represents a 'primary cause' for the patient's critical illness; and second, whether the surrogate may be harmed by failure to disclose HIV status. This balanced consideration of the direct duties of physicians to patients, and their indirect duties to surrogates and third-party contacts, may be used as a framework for considering other ethical obligations in the intensive care unit. We also provide a tabulation of individual US state laws relevant to disclosure of HIV status.
\end{abstract}

\section{Introduction}

Physicians treating newly incapacitated patients often must help navigate surrogate decision-makers through a difficult course of treatment decisions [1]. Because safeguarding the patient's autonomy often requires open discussion of the patient's condition with appointed surrogates [2,3], physicians have ethical duties to provide surrogates with complete and accurate information on which to base their decisions.

But how exacting are these duties? Under what circumstances, if any, may physicians intentionally withhold information about the incapacitated patient from surrogates? In this commentary, we use three cases as examples to guide intensive care physicians in addressing these difficult questions.

\section{Clinical cases}

\section{Case 1}

A 45 year old HIV-positive woman with an unknown $\mathrm{CD}_{4}$ count is admitted to an intensive care unit with 3 days of fever, chills, fatigue, and shortness of breath. Her blood cultures rapidly grow Staphylococcus aureus, and an echocardiogram is consistent with bacterial endocarditis. Septic shock and the acute respiratory distress syndrome develop. Prior to intubation, the patient asks that her daughter be her surrogate decision-maker, but that her daughter not be informed of the patient's HIV status. The patient's husband had died eight months earlier from an AIDS-related illness.

\section{Case 2}

A 48 year old man presents with acute hypoxemic respiratory failure requiring immediate intubation. The patient has advanced HIV disease complicated by AIDS wasting syndrome, disseminated candidiasis, and pulmonary hypertension, all of which have contributed to his poor functional status at baseline. He has declined antiretroviral therapy, has kept the source of his symptoms to himself, has never disclosed his HIV status to his living relatives, and has not engaged in sexual activities since he was diagnosed.

Despite initiating therapy with trimethoprim/sulfamethoxazole and glucocorticoids for Pneumosistis jiroveci pneumonia, the patient remains intubated and critically ill several weeks later. The physicians estimate that the patient's poor nutritional status and severe respiratory compromise make meaningful recovery highly unlikely. They ask the patient's next-of-kin to clarify the patient's wishes for aggressive care.

\section{Case 3}

A 55 year old HIV-positive woman with known severe chronic obstructive pulmonary disease presents with acute hypercarbic respiratory failure and requires urgent intubation. Prior to intubation, she asks the physician not to tell her husband that she is HIV-positive, expressing concern that he would hate her for being dishonest with him, and for putting him at risk during intercourse. 


\section{The ethical conflicts}

The patient in case 1 is critically ill due to several disease processes, which may or may not have been linked to her immunocompromised state. She poses no direct risk to her decision-maker. The patient in case 2 is critically ill due to a known complication of advanced HIV, and the patient's prior choices to forgo therapy for this disease may reflect the patient's underlying values and preferences for end-of-life care. Finally, the patient in case 3 is critically ill for reasons not clearly related to HIV, but her HIV disease is relevant because she has been sexually active with her surrogate decision-maker.

In case 1 , the physicians ideally would have obtained more information regarding the patient's treatment preferences prior to intubation. However, because patients may be unprepared or unable to have such a discussion while acutely ill, surrogates often provide the best information physicians can obtain to guide future management. When a pre-existing surrogate, or one with durable power of attorney for health care, is not available, physicians must often ascertain whether a newly designated surrogate is suitable. Specifically, a proper surrogate will: have an appropriate familial or otherwise legally recognized relationship to the patient; be capable of ascertaining and effectuating the patient's wishes and best interests; and not act from improper or personal motives.

Though many critically ill patients lack proper surrogates [4], when they exist, physicians are obliged to provide them with all relevant information about the patient's medical condition so that the surrogate can make an informed decision on the patient's behalf. Information about specific underlying diseases may be relevant to a proper consideration of the patient's current condition if it clarifies why the patient's condition is or is not potentially reversible, or if knowledge of how the patient previously chose to deal with this disease can clarify the patient's underlying values or beliefs.

In case 1, the physicians did not disclose the patient's HIV status to the daughter because the HIV infection was merely one of many potential reasons why the patient may have been so ill. Disclosure would not have enabled the daughter to better serve her role as surrogate decision-maker. Nondisclosure upheld both the physicians' duty to maintain the patient's confidentiality, and their duty to the surrogate to provide all necessary information to make an informed decision that served the patient's interests.

By contrast, in case 2, the father's HIV infection was a proximate determinant of his current clinical condition, and knowledge of how he previously chose to respond to this illness might usefully inform the daughter's consideration of how he would want to be managed in his current condition. Thus, disclosure of the father's severe HIV-related illnesses, and his prior choices to forgo therapy, may improve the daughter's ability to act as an appropriate surrogate in this case.
Importantly, failure to disclose the patient's underlying health condition risks minimizing opportunities for the timely withdrawal of painful or futile interventions. The physicians' obligation of beneficence to their patients is therefore relevant to the decision to disclose because doing so may ultimately serve the patients' interests in avoiding needless suffering [5]. In general, disclosure is justified when: the patient is at significant risk of unnecessary suffering; the action of others is needed to prevent this suffering; the action of others has a high probability of preventing it; and the benefit that the patient can be expected to gain outweighs any harms, costs, or burdens that others are likely to incur.

In addition, disclosure may be justified on legal and ethical grounds if nondisclosure poses a direct and foreseeable risk to the surrogate. In case 3, for example, failure to disclose the patient's HIV status to the husband may forestall his timely testing for a life-threatening but treatable infection. The Tarasoff case established that confidentiality must be breached if there is an imminent threat to an identifiable third party, or "the duty to warn" [6]. In case 3, privileging the HIVpositive wife by viewing her entitlement to confidentiality as unimpeachable, regardless of the potential harm to her husband, and possibly others through him, is unjust because it inappropriately places her rights above those of her husband.

Thus, when nondisclosure places third parties at serious and foreseeable risk, as for the husband in this case, obligations to disclose confidential information emerge [6].

Physicians disclosing such information must do so cautiously, however, because it is possible that surrogates may respond to such information with anger or resentment at not having been informed previously by the patients. In such cases, disclosure may impair the surrogate's ability to make decisions on the patient's behalf. If such impairment of a surrogate's decisional capacity is foreseen by the physician, it may be necessary to involve other family members, or even a court-appointed guardian, in discussions regarding the patient's medical care.

\section{Conclusions}

Disclosure of confidential information to surrogate decisionmakers of critically ill patients is justified under a narrow set of conditions. These conditions are limited to cases in which disclosure is necessary for the surrogate to make decisions that reflect the patient's values and interests, or when failure to disclose poses direct and foreseeable risks to the surrogate. We believe this ethical framework, exemplified by the foregoing cases, should guide physicians faced with such dilemmas in the intensive care unit. However, in several US states, established case law may also influence physicians' practices [7-14]. Although most states have not adopted specific statutes governing disclosure of confidential HIVrelated information, some have adopted laws that: prohibit 
Table 1

Laws of the 53 US states and territories: physician's disclosure of a patient's HIV status ${ }^{\text {a }}$

\begin{tabular}{lcl}
$\begin{array}{l}\text { Physician } \\
\text { notification } \\
\text { to a third party }\end{array}$ & $\begin{array}{c}\text { No. of states } \\
\text { (percent) }\end{array}$ & States \\
\hline $\begin{array}{l}\text { Required } \\
\text { Permitted }\end{array}$ & $1(1)$ & Michigan \\
& $10(19)$ & $\begin{array}{l}\text { Arizona, California, lowa, Kentucky, Massachusetts, New York, Pennsylvania, Rhode Island, } \\
\text { South Carolina, Texas } \\
\text { Prohibited }\end{array}$ \\
& $11(21)$ & $\begin{array}{l}\text { Alaska, Arkansas, Washington, DC, Georgia, Hawaii, Idaho, Mississippi, Puerto Rico, } \\
\text { South Dakota, Vermont, Virginia }\end{array}$ \\
No guidelines & $31(59)$ & $\begin{array}{l}\text { Alabama, Colorado, Connecticut, Delaware, Florida, Illinois, Indiana, Kansas, Louisiana, Maine, } \\
\text { Maryland, Minnesota, Missouri, Montana, Nebraska, Nevada, New Hampshire, New Jersey, } \\
\text { New Mexico, North Carolina, North Dakota, Ohio, Oklahoma, Oregon, Tennessee, Utah, }\end{array}$ \\
& & Virgin Islands, Washington, West Virginia, Wisconsin, Wyoming
\end{tabular}

alncludes all 50 US states, District of Columbia, Puerto Rico, and the Virgin Islands. bThe state law contains a specific statement that a health care provider (not a health agency) has a duty to disclose a patient's HIV status to at risk third parties under certain circumstances (for example, when the infected index patient refuses to disclose such information, or as long as the anonymity of the index patient is maintained). ${ }^{c}$ The state law neither requires nor prohibits but does allow a health care provider to disclose a patient's HIV status to at risk third parties (certain restrictions may apply, such as a requirement that physicians first encourage the index patient to disclose their status themselves). dThe state law contains a specific statement that a health care provider may not notify at risk third parties of a patient's HIV status. States encourage or allow court-ordered testing for HIV or third-party notification of a patient's HIV status in cases of sexual assault; however, these states also prohibit such practices in other cases, and are classified as prohibiting physician disclosure. eThere are no specific state laws regarding a physician's disclosure of a patient's HIV status to at risk third parties. States make no general comment on third-party notification, but require or prohibit it in cases of sexual assault; these are classified as providing no guidelines.

disclosure of HIV status, even when third parties are at risk; require disclosure in such cases; or permit disclosure in such cases after considering its risks and benefits [15]. We summarize these state laws in Table 1 for physicians' future reference.

\section{Competing interests}

The authors declare that they have no competing interests.

\section{References}

1. Jansen LA, Ross LF: Patient confidentiality and the surrogate's right to know. J Law Med Ethics 2000, 28:137-143.

2. In Re: Karen Ann Quinlan, matter of Quinlan http://www.csulb.edu/ jvancamp/452_r6.html.

3. In Re: Daniel Joseph Fiori, an adjudged incompetent. http://evans-legal.com/dan/fiori.html

4. White DB, Curtis JR, Lo B, Luce JM: Decisions to limit life-sustaining treatment in critically ill patients who lack both decision-making capacity and surrogate decision-makers. Crit Care Med 2006, 34:2053-2059.

5. Beauchamp TL, Childress JF: Beneficence. In Principles of Biomedical Ethics. 5th edition. Edited by Beauchamp TL, Childress JF. Oxford: Oxford University Press; 2001:165-224.

6. Tarasoff $\mathbf{v}$ Regents of the University of California. In Law and Bioethics an Introduction. 1st edition. Edited by Menikoff J. Washington DC: Georgetown University Press; 2001:176-181.

7. Gostin LO, Lazzarini Z, Neslund VS, Osterholm MT: The public health information infrastructure: a national review of the law on health information privacy. JAMA 1996, 275:1921-1927.

8. The Health Insurance Portability and Accountability Act of 1996 (HIPAA) [http://www.cms.hhs.gov/hipaa]

9. Branson BM, Handsfield HH, Lampe MA, Janssen RS, Taylor AW, Lyss SB, Clark JE: Revised recommendations for HIV testing of adults, adolescents, and pregnant women in health-care settings. MMWR Recomm Rep 2006, 55:1-17.

10. Fernandez H: Is AIDS different? Alb Law Rev 1998, 61:10531070.
11. Salmon S: The name game: issues surrounding New York State's HIV partner notification law. New York Law School J Hum Rights 2000, 16:959-991.

12. Gostin LO: HIV screening in health care settings Public health and civil liberties in conflict? JAMA 2006, 296:2023-2025.

13. Halpern SD: HIV testing without consent in critically ill patients. JAMA 2005, 294:734-737.

14. Hodge JG, Gostin KG: Challenging themes in American health information privacy and the public's health: Historical and modern assessments. J Law Med Ethics 2004, 32:670-679.

15. Law and Sexuality: a Review of Lesbian, Gay, Bisexual and Transgender Legal Issues [http://heinonline.org/HOL/ Index?index=journals/lsex\&collection=journals] 